\title{
Ethnic differences in the Prevalence of Thyroid disorders among population of Far Western Region of Nepal
}

\section{Dipendra Raj Pandeya ${ }^{1,3}$, Mahendra Prasad Bhatt ${ }^{2,3}$, Mahesh Prakash Bhatta ${ }^{3}$ and Janardhan Bhattarai $^{4}$}

1: Department of Clinical Laboratory Science, College of Applied Medical Sciences, Al Jouf University, Al Qurayyat, Saudi Arabia.

2: Gandaki Medical College Teaching Hospital and Research Center Pvt. Ltd. Pokhara, Nepal.

3: Life Care Diagnostics and Research Center Pvt. Ltd, Dhangadhi, Kailali, Nepal.

4: Department of Neuroscience, School of Medicine, University of Pennsylvania, USA.

\section{ABSTRACT}

Introduction: Thyroid disorder is second most common endocrine disorder after diabetes in the world. The burden of thyroid diseases in the general population is enormous especially in females. The aim of this paper is to study the prevalence of thyroid disorders among population of Far Western Region.

Methods: The present work was conducted to study the ethnic differences in the prevalence of thyroid disorders in patients who attended the Life Care Diagnostics and Research Center Pvt. Ltd. Dhangadhi. Total of 1000 patients suspected with thyroid disorders were enrolled in this study. The incidence of thyroid disorders and its relationship with the different ethnic, age groups and gender were investigated.

Results: Out of 1000 patients with suspected thyroid dysfunction, $65.8 \%$ were euthyroid followed by $13.8 \%$ of patients having subclinical hypothyroidism, 9.5\% hyperthyroidism and $7.9 \%$ hypothyroidism. The incidence subclinical hyperthyroidism 3.0\% was lowest. Hypothyroidism was the most common thyroid disorders among ethnic groups, Chhetri $37.97 \%$ and Brahmin $40.57 \%$. In addition, females were most affected among the population.

Conclusion: The prevalence of thyroid disorders in Far western population showed difference among different ethnic group. Public awareness of thyroid disorders and their potential complications could lead to improved diagnostic and therapeutic facilities.anti-snake venom.

Keywords: ethnic group; subclinical hyperthyroidism; subclinical hyperthyroidism

Correspondence: Dipendra Raj Pandeya, Department of Clinical Laboratory Science, College of Applied Medical Sciences, Al Jouf University, Al Qurayyat, Saudi Arabia.

To cite this article: Pandeya DR, Bhatt MP, Bhatta MP, Bhattarai J. Ethnic differences in the Prevalence of Thyroid disorders among population of Far Western Region of Nepal. Medical Journal of Shree Birendra Hospital. 2017;17(2):18-27.

DOI: http://dx.doi.org/10.3126/mjsbh.v16i2.18544

\section{Conflict of Interest: None declared}

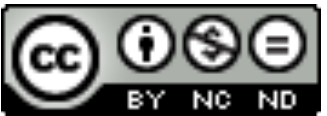

This work is licensed under creative common license: http://creativecommons.org/ licenses/by-nc-nd/4.0/ (C Medical Journal of Shree Birendra Hospital 


\section{INTRODUCTION}

Thyroid disorders are, arguably, among the most prevalent endocrine disorders around the globe other than diabetes mellitus. ${ }^{1}$ The most prevailing root of thyroid derangements worldwide is iodine deficiency and almost one-third of the world's population lives in the region of iodine inadequacy ${ }^{2}$. The burden of thyroid disease in the general population is enormous. Thyroid disorder is one of the major health issue in general population of Nepal and the number of thyroid patients are increasing day by day, with its prevalence of about $30 \%{ }^{3,4}$. Approximately, $0.2 \%$ of death has been reported in Nepal results from endocrine disorders. Among which iodine insufficiency has been major cause (World Health Organization., 2001). ${ }^{5}$ Even though the high prevalence of thyroid disorders, screening for these disorders is not favored by any main health department.

The Himalayan strip is one of the very extreme endemic parts for iodine deficiency condition.6,7 Nepalese population is at higher risk for thyroid dysfunction due to geographical locations with high hilly areas with higher prevalence of iodine deficiency disorders. ${ }^{8,9}$ Geographically, Nepal is divided into three ecological zones (Mountain, Hills and Terai), and culture is diverse, encompassing several ethnic sub-groups together with a number of different languages and religions. Nepal is composed of 125 caste/ethnic communities as mentioned in the 2011 census (CBS, 2012). Ethnic communities are grouped into 8 broad important groups Chhetri, Bahun, Hill Janajati, Terai Janajati, Terai different castes, Hill Dalit, Terai Dalit and Muslim. The ethnic communities have unique biological and genetic barrier. ${ }^{10}$ Because of these potential biological differences, genetic factors may be relevant to any ethnic comparison within Nepal. Geographically Kailali in Far western part of Nepal is located in the foothills of the Himalayas and made up of terai (flat lands). $40 \%$ of the land is covered by plain terai land $60 \%$ is covered by hills of Chure range. In places where the day-to-day iodine consumption is under $50 \mu \mathrm{g}$, goiter is usually endemic, and once the everyday consumption comes under $25 \mu \mathrm{g}$, hypothyroidism is seen. However, the prevalence and the pattern of thyroid disorders depend on ethnic and geographical factors, environmental factors and especially on iodine intake. ${ }^{11}$ Ethnic variation in prevalence may possibly reflect variations in genetic susceptibility due to polymorphisms or variations in environmental exposures (e.g., environmental contaminants).

Thyroid diseases are multifactorial with contributions from genetic and environmental factors. ${ }^{12}$ Thyroid dysfunction is usually acquired and may occur any time in life and is one of the chronic noncommunicable diseases affecting women more than men. Hypothyroidism and hyperthyroidism are two main thyroid disorders of which hypothyroidism are much more common. ${ }^{13}$ The prevalence status of hyperthyroidism (13.68\%) and hypothyroidism (17.19\%) were studied in the eastern part of Nepal. These disorders are 8 times more common in females than males. ${ }^{14}$ The actual reason is not known. The higher prevalence in females might be due to| estrogen and progesterone. 15 Furthermore, hypothyroidism may cause osteoporosis, hyperlipidemia and neuropsychiatry condition in the population. ${ }^{16}$

The thyroid hormones often referred as the major metabolic hormones; affect virtually every cell in the body. Thyroid disorder is defined as the abnormal thyroid stimulating hormones (TSH) with normal or abnormal thyroid hormones, free triiodothyronine ( $f$ T 3 ) and free tetraiodothyronine(fT4). ${ }^{14}$ The most common cause of thyroid dysfunction is a primary failure of thyroid gland, pituitary dysfunction, hypothalamic 
dysfunction or generalized tissue resistance to the circulatory thyroid hormones. Both hypothyroidism and hyperthyroidism have been linked with increased risk from cardiovascular disease and the adverse effects of thyrotoxicosis in terms of osteoporosis risk are well established. The seriousness of thyroid disorders should not be underestimated as thyroid storm and myxedema coma can lead to death in a significant number of cases. ${ }^{17}$ Virtually all studies report higher prevalence rates for hypothyroidism in women and with advancing age, with rates as high as $24 \%$ among women older than 60 years. ${ }^{18}$ Thyroid dysfunction is prevalent in pregnant women, with a morbidity of $2-3 \%$; it is caused by chronic autoimmune thyroiditis. The thyroid hormones frequently known as the important metabolic hormone, practically influence every cell in the body. Thyroid disorder is explained as the abnormal thyroid stimulating hormones (TSH) with normal or abnormal thyroid hormones, free triiodothyronine (f T3) and free tetra-iodothyronine (fT4). ${ }^{14}$ The most frequent reason behind thyroid dysfunction is a primary failure of the thyroid gland, pituitary dysfunction, hypothalamic dysfunction or generalized tissue resistance to the circulatory thyroid hormones. Hypothyroidism and hyperthyroidism have already been associated with increased risk from cardiovascular disease and the adverse effects of thyrotoxicosis with regards to osteoporosis risk are effectively established. The seriousness of thyroid problems should not be overlooked as thyroid storm and myxedema coma may result in death in a substantial number of cases. ${ }^{17}$ Almost all reports record higher prevalence rates for hypothyroidism in women and with developing era, with rates as high as $24 \%$ among women over the age of 60 years. ${ }^{18}$ Thyroid dysfunction is common in pregnant women, with a morbidity of $2-3 \%$; it is due to chronic autoimmune thyroiditis. ${ }^{19}$
The newborn may also be affected by hypothyroidism, which leads to irreversible mental and physical retardation if not identified early and treated properly. ${ }^{20}$

There is too little reliable and representative information on the prevalence of different types of thyroid disorders in Nepal. Numerous small studies from various parts of the nation carried out on the varied populations demonstrate different prevalence rates. ${ }^{11-13}$ Till now, these are no data reported regarding prevalence of thyroid disorders from Far western population of Nepal and this is the first study which is being reported from this region. There is much to learn about these disorders and their prevalence and their impact on health. So, early medical diagnosis along with treatment remains to be the essence of the management. Therefore, the investigation was designed along with an objective in order to measure the prevalence associated with thyroid disorder within the far western region of Nepal.

\section{METHODS}

Total 1,000 cases of suspected thyroid disorders of both the sexes of varying age groups ranging from one year to eighty years from Dhangadhi, Kailali district of the Far Western Region were included in the study. This study was conducted in the specialized diagnostic center of Dhangadhi, Nepal from September, 2016 to March, 2017. All the patients suspected of thyroid disorders were screened for thyroid function after obtaining consent from all the patients. $5 \mathrm{ml}$ of blood sample was collected and centrifuged at $3000 \mathrm{rpm}$ for 15 minutes for serum separation. Thyroid function was assessed by quantitative estimation of fT3, fT4 and TSH levels in serum performed using fully automated immunology analyzer (Beckman coulter, access 2, USA) based on Chemiluminescent Immuno Assay (CLIA). 
The reference interval for $\mathrm{fT}_{3}, \mathrm{fT}_{4}$ and TSH were 2.30-4.20 pg/ml, 0.61-1.12 ng/dl and 0.35-5.50 $\mathrm{mIU} / \mathrm{L}$ respectively. Thyroid function is considered normal (Euthyroidism) when subjects were presented with normal $\mathrm{fT}_{3}, \mathrm{fT}_{4}$ and $\mathrm{TSH}$. Abnormal thyroid function was further categorized as hyperthyroid (high $\mathrm{fT}_{3}$, $\mathrm{fT}_{4}$ and low $\mathrm{TSH}$ ), subclinical hyperthyroid (Normal $\mathrm{fT}_{3}, \mathrm{fT}_{4}$ and Low $\mathrm{TSH}$ ), hypothyroidism (low $\mathrm{fT}_{3}, \mathrm{fT}_{4}$ and high $\mathrm{TSH}$ ), and subclinical hypothyroidism (Normal $\mathrm{fT}_{3}$, fT4 and high TSH).

Statistical analysis was done using the Statistical Package for the Social Sciences (SPSS) version 20.0.The data were represented as counts, percentage and mean \pm standard deviation. Data were considered significant at $\mathrm{P}<0.05$.

\section{RESULTS}

A total of 1000 patients were enrolled into the study among whom $81.4 \%(n=814)$ were females and $18.16 \%(n=186)$ were males. The sex-wise analysis of these subjects is compared in Table 1. The ratio of female to male is around 4.3:1 in this study. The mean $\mathrm{FT}_{4}$ level in male and female group were $0.913 \pm 0.65$ and $0.85 \pm 0.52 \mathrm{pg} / \mathrm{ml}$ respectively which is statistically significant $(\mathrm{P}=0.043)$. However, FT3 $(3.9312 \pm 2.39$ and $3.74 \pm 2.4 \mathrm{pg} / \mathrm{ml}$, $\mathrm{P}=0.214)$ and TSH $(8.499 \pm 24.15$ and $8.81 \pm 24.74$ $\mu \mathrm{IU} / \mathrm{ml} ; \quad \mathrm{P}=0.879$ ) were did not show any significant difference in both groups.

All the patients enrolled in this group were divided into different ethnic groups like Brahmin, Chhetri, Thakuri, Tharu, Rana, Newar and others. The

Table 1: Prevalence of thyroid dysfunctions in Male and Female groups

\begin{tabular}{|c|c|c|c|}
\hline Thyroid Hormones & Male (Mean \pm SD) & Female (Mean \pm SD) & $P$ value \\
\hline Free T3 (pg / ml) & $3.9312 \pm 2.39$ & $3.74 \pm 2.4$ & 0.214 \\
\hline Free T4 (pg / ml) & $0.913 \pm 0.65$ & $0.85 \pm 0.52$ & $0.043^{*}$ \\
\hline TSH $(\mu \mathrm{IU} / \mathrm{ml})$ & $8.499 \pm 24.15$ & $8.81 \pm 24.74$ & 0.879 \\
\hline Total & 186 & 814 & \\
\hline
\end{tabular}

Table 2: Distribution of different thyroid disorders according to ethnicity. P value was 0.11 .

\begin{tabular}{|c|c|c|c|c|c|c|}
\hline \multirow{2}{*}{ Ethinicity } & \multicolumn{5}{|c|}{ Thyroid disorders } & Total \\
\hline & Euthyroidism & Hypothyroidism & $\begin{array}{c}\text { Subclinical } \\
\text { Hypothyroidism }\end{array}$ & $\begin{array}{c}\text { Hyper- } \\
\text { thyroidism }\end{array}$ & $\begin{array}{c}\text { Subclinical } \\
\text { hyperthyroidism }\end{array}$ & \\
\hline Brahmin & $187(66.31 \%)$ & $21(7.44 \%)$ & $42(14.89 \%)$ & $25(8.86 \%)$ & $7(2.48 \%)$ & 282 \\
\hline Chhetri & $204(67.10 \%)$ & $30(9.86 \%)$ & $32(10.52 \%)$ & $30(9.86 \%)$ & $8(2.63 \%)$ & 304 \\
\hline Thakuri & $86(74.78 \%)$ & $3(2.6 \%)$ & $17(14.78 \%)$ & $5(4.34 \%)$ & $4(3.47 \%)$ & 115 \\
\hline Tharu & $56(58.33 \%)$ & $4(4.16 \%)$ & $15(15.62 \%)$ & $16(16.66 \%)$ & $5(5.20 \%)$ & 96 \\
\hline \multirow{2}{*}{ Rana } & $11(68.75 \%)$ & $1(6.25 \%)$ & $2(12.5 \%)$ & $2(12.5 \%)$ & 0 & 16 \\
\hline Newar & $6(60 \%)$ & 0 & $3(30 \%)$ & 0 & $1(10 \%)$ & 10 \\
\hline Others & $108(61.01 \%)$ & $20(11.29 \%)$ & $27(15.25 \%)$ & $17(9.6 \%)$ & $5(2.82 \%)$ & 177 \\
\hline Total & $658(65.8 \%)$ & $79(7.9 \%)$ & $138(13.8 \%)$ & $95(9.5 \%)$ & $30(3.5 \%)$ & 1000 \\
\hline
\end{tabular}


Table 3: Distribution of different thyroid disorders according to the age group. $P$ value was 0.01

\begin{tabular}{|l|c|c|c|c|c|}
\hline \multicolumn{1}{|c|}{ Thyroid status } & \multicolumn{5}{|c|}{ Age Group } \\
\hline & $\leq 15$ & $16-30$ & $31-44$ & $45-60$ & $\geq 61$ \\
\hline Euthyroidism & $7(43.75 \%)$ & $254(72.15 \%)$ & $246(62.91 \%)$ & $118(64.48 \%)$ & $33(56.89 \%)$ \\
\hline Hypothyroidism & 0 & $23(6.53 \%)$ & $33(8.43 \%)$ & $15(8.19 \%)$ & $8(13.79 \%)$ \\
\hline Subclinical Hypothyroidism & $4(25 \%)$ & $34(9.65 \%)$ & $56(14.32 \%)$ & $36(19.67 \%)$ & $8(13.79 \%)$ \\
\hline hyperthyroidism & $5(31.25 \%)$ & $31(8.80 \%)$ & $44(11.25 \%)$ & $9(4.91 \%)$ & $6(10.34 \%)$ \\
\hline Subclinical hyperthyroidism & 0 & $10(2.84 \%)$ & $12(3.06 \%)$ & $5(2.73 \%)$ & $3(5.17 \%)$ \\
\hline Total & 16 & 352 & 391 & 183 & 58 \\
\hline
\end{tabular}

patients were classified by thyroid function based on $\mathrm{FT}_{3}, \mathrm{FT}_{4}$ and $\mathrm{TSH}$ levels, and categorized into different groups like euthyroidism, hypothyroidism, sub-clinical hypothyroidism, hyperthyroidism and sub-clinical hyperthyroidism. The prevalence of each group were reported as percentages. Based on this $65.8 \%, 7.9 \%, 13.8 \%, 9.5 \%$ and $3.5 \%$ for euthyroidism, hypothyroidism, subclinical hypothyroidism, hyperthyroidism, and subclinical hyperthyroidism, respectively. The distribution of thyroid disorders in different ethnic group is shown in Table 2.

Our result shows among the ethnic groups, most of the thyroid disorders are noticed in Chhetri (hypothyroidism 37.97\%, hyperthyroidism 31.37\% and subclinical hyperthyroidism $26.66 \%$ ). However, prevalence of subclinical hypothyroidism was noticed higher in Brahmin 40.57\%. In addition, both Brahmin and Chhetri ethnic groups have higher prevalence rate then the other ethnic groups. The difference between these groups was not statistically significant. The lowest prevalences were observed among the Thakuri, Tharu, Rana, Newar and others.

Frequency of thyroid disorder was noticed highest in the age group of 31-44 years and lowest were shown in $<15$ years and $>61$ years. In addition, hypothyroidism $41.77 \%$, subclinical hypothyroidism $40.57 \%$, hyperthyroidism $46.31 \%$, and subclinical hyperthyroidism $40 \%$ were noticed. In addition, data revealed significant association with different age groups $(P=0.01)$. As compared to younger and older people, middle age adults (16-44 years) have slightly greater chances of being diagnosed of thyroid disorders. Similarly, all the thyroid disorder percentage is shown in Figure 1. Distribution of $\mathrm{FT}_{3}$ was noticed statistically significant in different ethnic groups $(\mathrm{P}=<0.05)$. However, no significant difference was noticed in $\mathrm{FT}_{4}$ and TSH among different ethnic groups (Table 3-5).

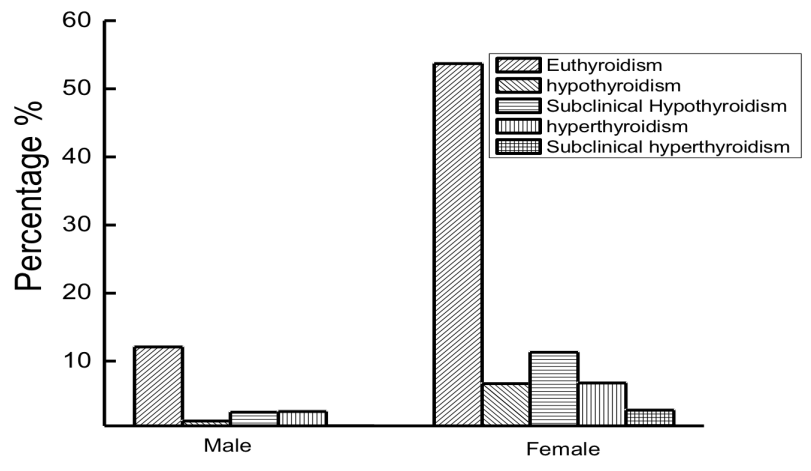

Figure 1: Prevalence of thyroid dysfunctions in Male and Female groups 
Table 4: Distribution of T3 according to the ethnicity. P value was 0.05

\begin{tabular}{|l|c|c|c|c|}
\hline \multicolumn{1}{|l|}{ Ethnicity } & \multicolumn{3}{|c|}{ FT3 } & Total \\
\hline Brahmin & Low & Normal & High \\
\hline Chhetri & $4(1.41 \%)$ & $254(90.07 \%)$ & $24(8.51 \%)$ & 282 \\
\hline Thakuri & $12(3.94 \%)$ & $263(86.51 \%)$ & $29(9.53 \%)$ & 304 \\
\hline Tharu & 0 & $111(96.52 \%)$ & $4(3.48 \%)$ & 115 \\
\hline Rana & $1(1.04 \%)$ & $79(82.29 \%)$ & $16(16.66 \%)$ & 96 \\
\hline Newar & 0 & $14(87.5 \%)$ & $2(12.5 \%)$ & 16 \\
\hline Others & $1(10 \%)$ & $9(90 \%)$ & 0 & 10 \\
\hline Total & $26(2.5 \%)$ & $153(86.44 \%)$ & $16(9.03 \%)$ & 177 \\
\hline
\end{tabular}

Table 5: Distribution of T4 according to the ethnicity. P value was 0.14

\begin{tabular}{|c|c|c|c|c|}
\hline \multirow[t]{2}{*}{ Ethnicity } & \multicolumn{3}{|c|}{ FT4 } & \multirow[t]{2}{*}{ Total } \\
\hline & Low & Normal & High & \\
\hline Brahmin & $18(6.38 \%)$ & $245(86.87 \%)$ & $19(6.73 \%)$ & 282 \\
\hline Chhetri & $28(9.21 \%)$ & $261(85.85 \%)$ & $15(4.93 \%)$ & 304 \\
\hline Thakuri & $3(2.6 \%)$ & $107(93.04 \%)$ & $5(4.34 \%)$ & 115 \\
\hline Tharu & $4(4.16 \%)$ & $82(85.41 \%)$ & $10(10.41 \%)$ & 96 \\
\hline Rana & 0 & $14(87.5 \%)$ & $2(12.5 \%)$ & 16 \\
\hline Newar & 0 & $10(100 \%)$ & 0 & 10 \\
\hline Others & $16(9.03 \%)$ & $153(86.44 \%)$ & $8(4.51 \%)$ & 177 \\
\hline Total & $69(6.9 \%)$ & $872(87.2 \%)$ & $59(5.9 \%)$ & 1000 \\
\hline
\end{tabular}

\section{DISCUSSION}

Thyroid disorder prevalence studies have allowed for worthy insights in discerning the epidemiology of thyroid disorders in population everywhere in the world. Nepal, a Himalayan country, lies in the severe ambient iodine deficiency zone and has a very high prevalence of iodine deficiency disorders (IDD). ${ }^{21}$ There is a rise in the prevalence of all the thyroid disorders in Nepal. However, screening studies have been a rarity in Nepal and there is scanty literature on prevalence of these disorders in all regions of Nepal. In our research most people evaluated the prevalence associated with thyroid disorders in various ethnic communities living in Kailali district of Far Western Region. This study is among the very first of its kind to examine ethnic variations in thyroid problems in the far western part of Nepal. The prevalence and the pattern of thyroid problems are determined by ethnic, geographical, and environmental factors, which including the iodine intake status. 22 The prevalence associated with thyroid disorders may differ around 
Table 6: Distribution of TSH according to the ethnicity. P value was 0.5

\begin{tabular}{|l|c|c|c|c|}
\hline \multicolumn{1}{|l|}{ Ethinicity } & \multicolumn{4}{|c|}{ TSH } \\
\hline & Low & Normal & High \\
\hline Brahmin & $26(9.21 \%)$ & $198(70.21 \%)$ & $58(20.56 \%)$ & 282 \\
\hline Chhetri & $24(7.89 \%)$ & $218(71.71 \%)$ & $62(20.39 \%)$ & 304 \\
\hline Thakuri & $9(7.82 \%)$ & $86(74.78 \%)$ & $20(17.39 \%)$ & 115 \\
\hline Tharu & $15(15.62 \%)$ & $62(64.58 \%)$ & $19(19.79 \%)$ & 96 \\
\hline Rana & $3(18.75 \%)$ & $11(68.57 \%)$ & $2(12.5 \%)$ & 16 \\
\hline Newar & $1(10 \%)$ & $7(70 \%)$ & $2(20 \%)$ & 10 \\
\hline Others & $15(8.47 \%)$ & $117(66.10 \%)$ & $45(25.42 \%)$ & 177 \\
\hline Total & $93(9.3 \%)$ & $699(69.9 \%)$ & $208(20.8 \%)$ & 1000 \\
\hline
\end{tabular}

several parts of nations around the world ${ }^{11-13}$ associated with diverse economic prosperity. However, it is unclear if these types of variations result from ethnic, environmental as well as economic reasons.

This study shows an overall $34.2 \%$ prevalence of thyroid disorders in the Far western population. $81.4 \%$ of the study subjects were women and $18.6 \%$ were male. In our study, the proportion of females having thyroid disorder is high. This is in accordance with the previous reports $23-25$ that could be due to a sex difference in the prevalence of autoimmune disorders. ${ }^{26}$ Despite all age groups suffering from thyroid dysfunction, a significant number of cases were observed in the age group of 31-44 years in our study. Similar results were reported by other studies. ${ }^{14-26}$ This study illustrates subclinical hypothyroidism was found to be common type of thyroid disorder affecting $13.8 \%$ population, followed by hyperthyroidism $(9.5 \%)$, hypothyroidism $7.9 \%$ and subclinical hyperthyroidism mainly, was alarmingly high in this region with female vulnerability. However, a study reported by Adhikari BR, et al. ${ }^{27}$ in Bharatpur General Hospital revealed hypothyroidism (87.0\%) followed by hyperthyroidism $11.2 \%$ and subclinical hypothyroidism $1.9 \%$. In addition, study by Aryal et al. ${ }^{3}$ reported hypothyroidism $8 \%$, subclinical hypothyroidism $8 \%$, subclinical hyperthyroidism $6 \%$ and hyperthyroidism $3 \%$ respectively. The prevalence of hypothyroidism was more substantial in the age group of 31-44 years followed by aged group 16-30 years. On the other hand different studies noted that of subclinical thyroid condition was discovered to be higher in the age group of 40-60 years like that reported by Holowell et al. ${ }^{28}$ This might be as a result of the reduced number of elderly aged people being referred to the test.

The mean FT4 level in our study show significant difference in male and female $(P=<0.05)$. However, FT3 and TSH data did not reveal any significant difference in both groups. However, similar findings were not supported in previous report by Yadav et. al. ${ }^{29}$ with respect to gender. The prevalence of thyroid disorders is different among different ethnic groups but data did not showed any significant difference among these groups. Our study revealed that Chhetri, and Brahmin are most affected by thyroid disorders compared to Thakuri, Tharu, Rana and Newar groups. Among total thyroid disorders Chhetri had 30\% hypothyroidism, $32 \%$ subclinical hypothyroidism, $30 \%$ 
hyperthyroidism and $8 \%$ subclinical hyperthyroidism. However, Brahmins had 22.20\% hypothyroidism, $44.21 \%$ subclinical hypothyroidism, 26.31\% hyperthyroidism and $7.36 \%$ subclinical hyperthyroidism. Thus, each group might have a distinct social and genetic make-up that has been maintained by the physical limitations of hills and valleys, and the cultural and social limitations of common marriage within ethnicity. ${ }^{30}$ In addition, these groups in our study, Brahmin, Chhetri, Thakuri, Tharu, Rana, and Newar, vary from one another significantly in several of facets of life for example ancestry, life experiences and roles within society.

Therefore, besides life style factors, ethnic, particular genetic components might also influence hormone levels. Population groups with variations identified by culture, religion or ethnicity also display variations with regards to disease, behaviour and beliefs and also vary genetically, to ensure that some disorders are more prevalent in certain ethnic groups. These various cultural contexts may equally put individuals at an increased risk of having a disorder and also influence the outcome.

The distribution of thyroid problems among the various ethnic communities was more prevalent in younger age groups compared to the older age. Both ethnic groups Chhetri and Brahmin had a greater prevalence of thyroid disorder in comparison to other ethnic groups. It is therefore important to determine age-specific tendencies in thyroid disorder among young and middle age groups in this region. One of the limitations in this study is that our results are only generalizable to Brahmin, Chhetri, Thakuri, Tharu, Rana, and Newar in Nepal. In particular, people may not associate the signs and symptoms with the disease process and thus may not bring them to the attention of themselves against thyroid disorder. For this reasons, if early detection of these disorders would be possible then, it would not become any life threatening problem.

\section{CONCLUSION}

In this study, we describe new evidence on variations in thyroid disorders indifferent ethnic groups in Far western Nepal. The observed differences suggest that ethnicity should be considered in screening and for the development of preventive strategies for thyroid disorders. The source of the ethnic variations in incidence remains uncertain, but doesn't appear to be clearly genetic: intergenerational social and cultural factors appear to modulate the biology of the disease. For more insight on the association of ethnic differences among thyroid disorders, more detailed study on large number of population is required.

\section{REFERENCES}

1. Sartorius N, Ustun TB, Lecrubier Y, Wittchen HU. Depression comorbid with anxiety: results from the WHO study on psychological disorders in primary health care. Br J Psychiatry 1996;177:38-43. PMID: 8864147

2. Zimmerman MB. Iodine deficiency. Endocr Rev 2009;30:376-408.

DOI: https://doi.org/10.1210/er.2009-0011

3. Aryal M, Gyawali P, Rajbh N, Aryal P, Raj D. A prevalence of thyroid dysfunction in Kathmandu University Hospital, Nepal. Biomedical Research. 2010;21(4):411-5. 
4. Chaudhari RK, Gelal B, Brodie D, Baral N. Thyroid function \& urinary iodine status in primary school age children of the hills \& plains of Eastern Nepal. Indian pediatrics. 2012(49):332-3. PMid:22565084

5. Mahato R, Jha B, Singh K, Yadav B, Shah S, Lamsal M. Status of Thyroid disorders in Central Nepal: A Tertiary care Hospital based study. International Journal of Applied Sciences and Biotechnology. 2015;3(1):119-22.

DOI: https://doi.org/10.3126/ijasbt.v3i1.12218

6. Ramalingaswami U. Endemic goiter in Southeast Asia, new clothes in an old boy. Ann Intern Med 1973;78:277-83.

DOI: https://doi.org/10.7326/0003-4819-78-2-277

7. Kapil U, Sharma TD, Singh P. Iodine status and goiter prevalence after 40 years of salt iodization in the Kangra district, India. Indian J Pediatr 2007;74(2):135-7.

DOI: https://doi.org/10.1007/s12098-007-0005-2

8. Baral N, Ramaprasad C, Lamsal M, Koner B, Koirala S. Assay of iodine deficiency status in three ecological regions of Nepal by a microdigestion method. 1999(30):527-31.

9. Gelal B, Aryal M, Das BL, Bhatta B, Lamsal M, Baral N. Assessment of iodine nutrition status among school age children of Nepal by urinary iodine assay. Southeast Asian Journal of Tropical Medicine and Public Health. 2009;40(3):538-43. PMid:19842441

10. Alan R. Templeton. Biological Races in Humans. Stud Hist Philos Biol Biomed Sci. 2013; 44(3):262-71. DOI: https://doi.org/10.1016/j.shpsc.2013.04.010

11. Laurberg P, Pederson KM, Hreidarsson A, Sigfusson N, Iversen E \& Knudsen PR. Iodine intake and the pattern of thyroid disorders: a comparative epidemiological study of thyroid abnormalities in the elderly in Iceland and in Jutland, Denmark. J Clin Endocrinol Metab 1998; 83:765-9.

DOI: https://doi.org/10.1210/jcem.83.3.4624

12. Tsegaye B, Ergete W. Histophathological pattern of thyroid disease. East Afr Med J. 2003;80:525-8. PMid:15250625

13. Mahato R, Nepal A, Gelal B, Poudel B, Yadav B, Lamsal M. Spectrum of thyroid dysfunction in patients visiting Kantipur Hospital, Kathmandu, Nepal. Mymensingh medical journal: MMJ. 2013;22(1):164-9. PMid:23416825

14. Vanderpump M. Epidemiology of thyroid dysfunction-Hypothyroidism and Hyperthyroidism. Thyroid international. 2009;2:3-12.

15. Nimmy N, Aneesh P, Narmadha M, Udupi R, Binu K. A survey on the prevalence of thyroid disorder induced by demography and food habits in South Indian population. Indian Journal of Pharmacy Practice. 2012;5(2)49-52.

16. Hitman s, Kelly F C, Prevalence of congenital hypothyroidism. Indian Journal of Endocrinology. 1999;45(4):245-9.

17. Hak AE, Pols HA, Visser TJ, Drexhage HA, Hofman A, Witteman JC. Subclinical hypothyroidism is an independent risk factor for atherosclerosis and myocardial infarction in elderly women: the Rotterdam Study. Annals of internal medicine. 2000;132(4):270-8. 
DOI: https://doi.org/10.7326/0003-4819-132-4-200002150-00004 PMid:10681281

18. Canaris GJ, Manowitz NR, Mayor G, Ridgway EC. The Colorado thyroid disease prevalence study. Archives of internal medicine. 2000;160(4):526-34. https://doi.org/10.1001/archinte.160.4.526 PMid: 10695693

19. Zhang Y, Wang H, Pan X, Teng W, Shan Z. Patients with subclinical hypothyroidism before 20 weeks of pregnancy have a higher risk of miscarriage: A systematic review and meta-analysis. PloS one. 2017;12(4):e0175708.

DOI: https://doi.org/10.1371/journal.pone.0175708 PMid:28414788

20. Vinayak Aghav, Tandle V. Hypothyroidism among rural population: A hospital based study. International Journal of Recent Trends in Science and Technology. 2017;22(2):90-3.

21. Pandav CS. IDD in Southeast Asia. In: Hetzel BS, Pandav CS, eds. SOS for a billion, the conquest of iodine deficiency disorders. Delhi: Oxford University Press, 1994: 213-31.

22. Baral N, Lamsal M, Koner BC, Koirala S. Thyroid dysfunction in eastern Nepal. Southeast Asian J Trop Med Public Health. 2002; 33:638-41. PMid:12693603

23. Sisk J. Thyroid disease in women. Thyroid 2005;17:34-8.

24. Jimmy A, Celine TM, Chacko M. Spectrum of thyroid disorders: A retrospective study at a medical college hospital. Thyroid arch and Practice. 2014;11:55-9.

DOI: https://doi.org/10.4103/0973-0354.129725

25. Ikem R, Adebayo J, Soyoye D, Burolaojo, Ugwu E, Kolawole B. Spectrum of thyroid disorders in Obafemi Awolowo University teaching hospital complex. Endocrine 2010;21:366-9.

26. Bell RJ, Davison SL, Topliss DJ, Donath S, Davis SR. Well being, health related quality of life and cardiovascular disease risk profile in women with subclinical thyroid disease- a community based study. Clin Endocrinol 2007;66:548-56.

DOI: https://doi.org/10.1111/j.1365-2265.2007.02771.x

27. Pradip Kumar S, Baijayanti B, Soma G, Thyroid stimulating hormone measurement as the confirmatory diagnosis of hypothyroidism: A study from a tertiary care teaching hospital Kolkata. Indian J Community Med 7;32:139-40.

28. Hollowell JG, Staehing NW, Flanders WD et al. Serum TSH, T4, and thyroid antibodies in the United States Population (1988 to 1994): National Health and Nutrition Examination Survey (NHANES III). J Clin Endocrinol Metabol 2002;87:489-99

DOI: https://doi.org/10.1210/jcem.87.2.8182 PMid:11836274

29. Yadav NK, Thanpari C, Shrewastwa MK, Mittal RK, Koner BC. Assessment of Thyroid Disorder in FarWestern Part of Nepal: A Hospital Based Study. Bangladesh Journal of Medical Science.2012;11: 303-6. https://doi.org/10.3329/bjms.v11i4.12601

30. Eibner C, Sturn R, Gresenz CR. Does relative deprivation predict the need for mental health services. J Ment Health Policy Econ. 2004;7:167-75. PMid:15701932 